\title{
Estimation of Hydrological Outputs using HEC-HMS and GIS
}

\author{
Olayinka D. N. ${ }^{1, *}$ and Irivbogbe H. E. ${ }^{2}$ \\ ${ }^{1}$ Department of Surveying \& Geoinformatics, Faculty of Engineering, University of Lagos, Lagos, Nigeria. \\ ${ }^{2}$ Hesi-Geomatics Limited, Lagos State, Nigeria. \\ Corresponding Author: *nihinolayinka@yahoo.co.uk
}

\begin{abstract}
Estimating runoff and understanding of the relationship between rainfall and runoff are of great importance in the management of flood. Several computer based hydrological models have been developed and used in simulating runoff in various watersheds in different parts of the world and in water resource studies. This study focuses on the combination of Geographic Information System (GIS) with Hydrologic Engineering Center -Hydrologic Modelling System (HEC-HMS) hydrological model to simulate runoff process of the adjoining areas of the Lagos Island and Eti-Osa Local Government Areas (LGAs). The study makes use of LIDAR Digital Elevation Model (DEM), drainage data and land use map for catchment delineation and hydrological modelling, using HECGeoHMS and ArcGIS 10.2. In HEC-HMS 4.2.1, the delineated catchment with all hydrological parameters and average daily rainfall data, are used to simulate and compute rainfall runoff volume, peak discharges for 10 months (between Jan to October) and a total of three years (2012, 2015 and 2017) were considered. Direct runoff volume and depth estimation for the years under review were determined. Results show that the peak discharge occurred on the 2 nd of July 2012 at a rate of $14 \mathrm{~m} 3 / \mathrm{s}$ with an estimated runoff volume at the basin outlet of 39,669.70 x $103 \mathrm{~m} 3$ (this date tallies with the severe flood events that occurred in that year). The study shows that estimating hydrological outputs is possible with the use of HEC-HMS and GIS. It recommends the application of such technologies in the prediction and development of basic flood warning systems for the area.
\end{abstract}

Keywords: Hydrological Outputs, Flooding, HEC-HMS, LIDAR, DEM, GIS

\subsection{Introduction}

Modelling and predicting floods are of great importance in the management of floods in an urban area and one of the common factors that cause flooding in most urban areas is heavy rainfall and the presence of impervious surfaces. Simulating hydrological outputs such as rainfall runoff volume, runoff depth and water availability of a catchment directly affect flood prediction results. Accurately determining these hydrological outputs over a period, will aid the development of reliable flood early warning systems. With the advent of climate change, the normal hydrological cycle of various river basins and locations all over the world is threatened; this is due to rise in temperature because of the global warming effect, associated in disturbing the frequency and intensity of precipitation over a given climatic condition (Sintayehu, 2015). Because of this, continuous simulation of hydrological outputs for such locations will aid proper flood modelling and prediction.

Surface runoff estimation is a common analyses in hydrology and due to the fact that measuring all parameters that bring about a watershed runoff is not possible, making use of a model that has a simple structure, minimum input data requirements, suitable for determination of such hydrological parameters and has a judicious precision is important. This means that estimating hydrological outputs especially for locations that do not have can be better carried out at any point in time due to the availability of such models. Hydrologic Engineering Center-Hydrologic Modelling System (HEC-HMS) is one of the models that meet these criteria. It has been widely used in different studies and at different times.

Majidi and Shahedi (2012) used HEC-HMS in estimating surface runoff in the Abnama watershed in Iran and this was based on the rate-received precipitation and quantifying discharge at outlet. They used 
different methods like Green-Ampt, SCS Unit hydrograph and Muskingum routing for the estimation process. Hadi et al (2012) used another approach that involved the use of HEC-HMS and Hydrologic Engineering Center-River Analysis System (HEC-RAS) models to simulate runoff in Karun River, Iran. The modelling process offered in their study includes the use of some of the recently developed GIS tools for map production. Reshma T. et al (2013) carried out the simulation of an even based runoff using HEC-HMS model and the Walnut Gulch watershed located in Arizona, USA, was the case study. Computation of infiltration, rainfall excess conversion to runoff and flow routing were carried out and according to their work, the model performed satisfactorily and provided reliable results. In Ghana, Yaw et al., (2015) simulated Flood Volume of Dikpe Catchment using HEC-HMS. Results obtained were compared with the result gotten from direct computation of the precipitation volume and this provided satisfactory results. Olayinka and Irivbogbe (2017) used HEC-HMS and HEC-RAS in modelling and mapping flood vulnerable areas and the results obtained and validation carried out were very satisfactory.

From the above studies, it shows that the HEC-HMS model is an effective tool that can be used for the precise simulation of the hydrology outputs of watersheds. This present study focuses on the use of HEC-HMS and GIS in the determination of hydrological parameters and the estimation of hydrological outputs such as rainfall runoff, runoff depth and peak discharges within the study area for different years.

\subsection{Methodology}

\subsection{Location of study}

This study focuses on the adjoining areas of two Local Government Areas (LGAs) in Lagos state Lagos Island and Eti-Osa Local Government Area (covering Ikoyi, Lekki Phase 1 and Victoria Island). These areas are dynamic in nature. The location share boundaries on the North with Lagos Lagoon, the largest coastal lagoon in Western Africa. Eti-Osa LGA directly shares its boundary on the south with the Atlantic Ocean. This location is densely populated and it covers a total land area of approximately 28 square kilometres. It is located within Latitude $6^{\circ} 26^{\prime} 34^{\prime \prime} \mathrm{N}$ and Longitude $3^{\circ} 24^{\prime} 30^{\prime \prime} \mathrm{E}$ on the left and Latitude $6^{\circ} 29^{\prime} 04^{\prime \prime} \mathrm{N}$ and Longitude $3^{\circ} 39^{\prime} 09^{\prime \prime} \mathrm{E}$ on the right. This location can be described as a place with a variety of land uses. It is a notable commercial area but also has a mixture of residential and institutional land uses.

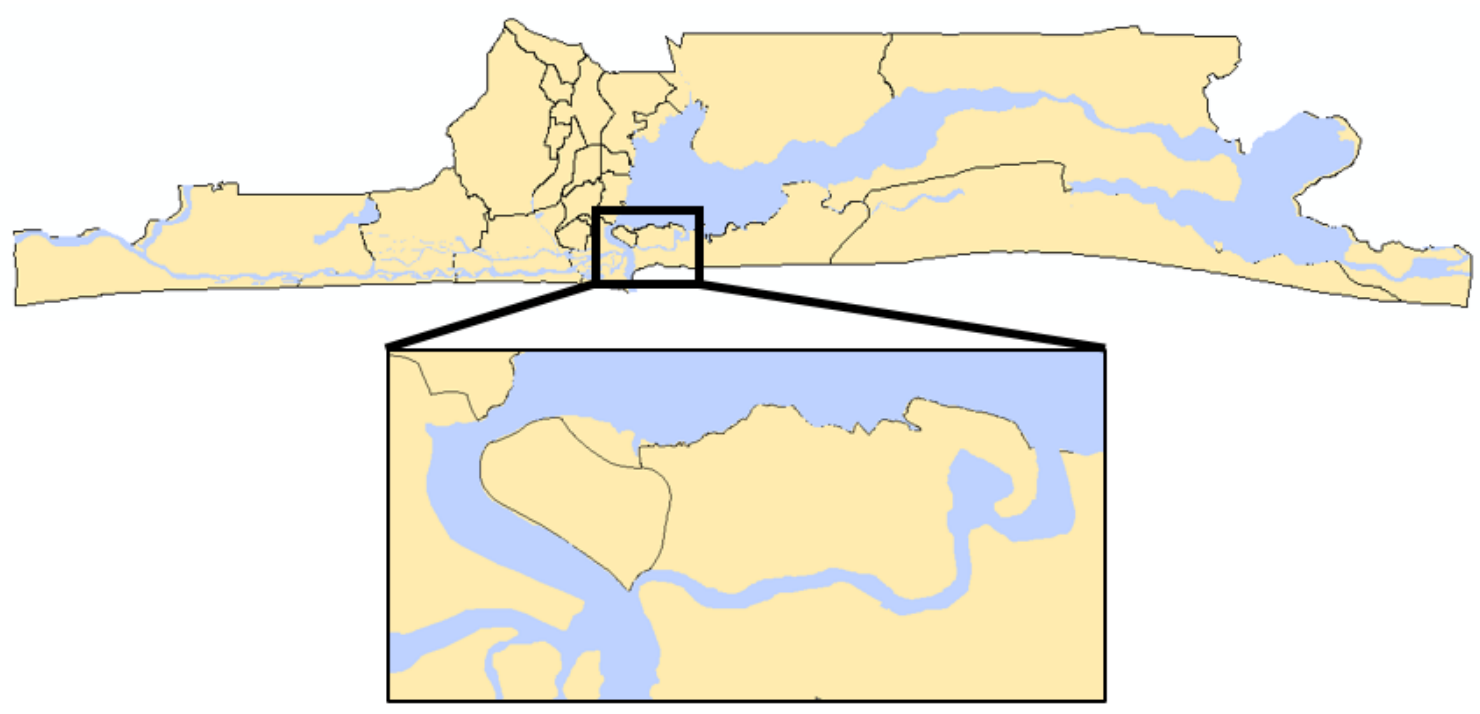

Figure 1: Representation of the Study area 


\subsection{Data acquisition}

Most of the data acquired for this study are from secondary sources. The data used include:

i. LIDAR DEM acquired in the year 2008, in classified text file format, covering the study area was obtained from the Office of the Surveyor General of Lagos State. A 5m resolution DEM was created from the text files.

ii. Drainage network covering the main channels of the study area from the Lagos State Drainage network manual produced in the year 2012.

iii. Landuse map covering the study area for the year 2002 was obtained from the Ministry of Physical Planning, Lagos State.

iv. Landuse map covering the western part (Banana Island inclusive) of the study area, for the year 2011.

v. Average Daily Precipitation data spanning a total period of 10 months ( $\left(1^{\text {st }}\right.$ January $-31^{\text {st }}$ October from year 2012 to year 2017) from Tropical Rain Measuring Mission (TRMM) Online Visualization and Analysis System (TOVAS), a member of Giovanni (GES-DISC Interactive Online Visualization and Analysis Infrastructure).

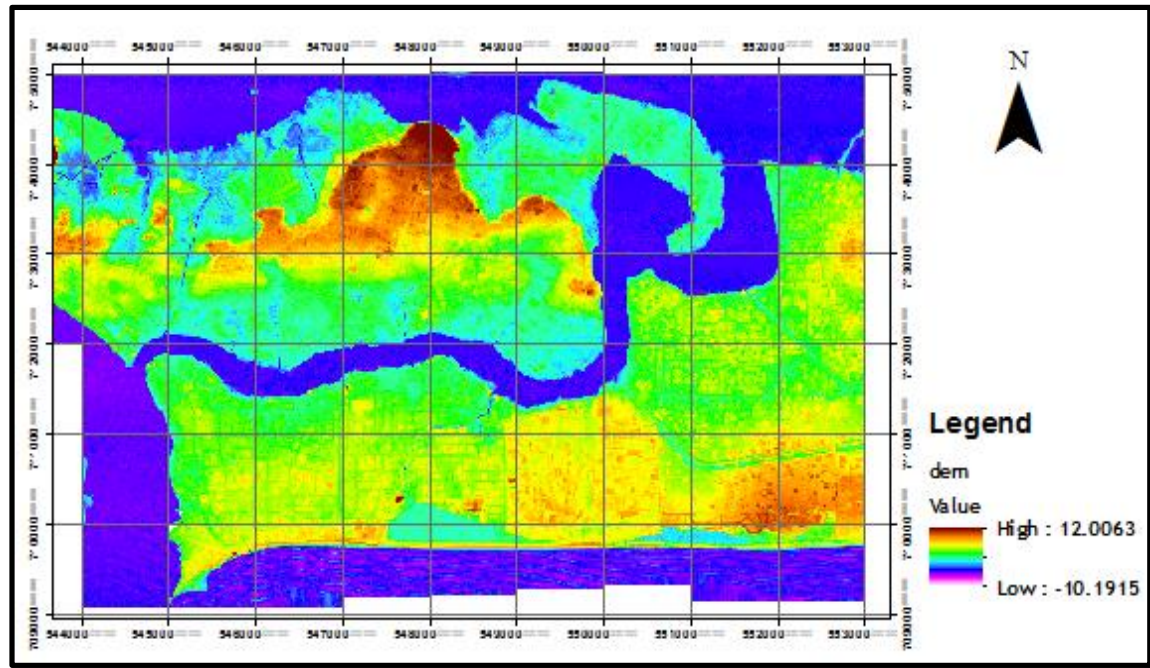

Figure 2: Digital Elevation (DEM) of the study area

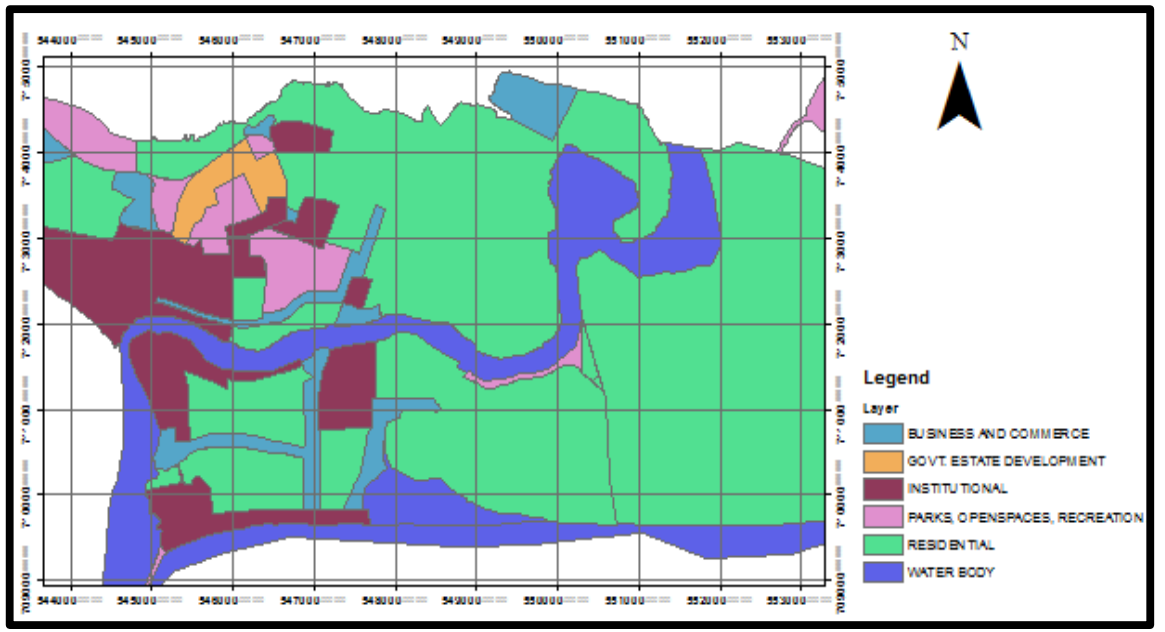

Figure 3: Landuse map of the study area 


\subsection{HEC-HMS and Soil Conservation Service (SCS)}

The HEC-HMS Hydrological Model (developed by the United States Hydrologic Engineering Centre) provides a platform over which robust hydrological modelling with the incorporation of accurate spatial data can be carried out. This modelling package has been used in various research works and it has been proven to be very helpful and viable in flood modelling, monitoring and management (Horritt and Bates, (2002); Bates, (2004); Knebl et al., (2005); Castellarin et al., (2009)). The model is compatible with GIS applications like ArcGIS and it is suitable for the study area because over time, it has shown good practical use in modelling and management of runoff and floods respectively.

Over time, the HEC-HMS model is used to transform precipitation data into direct flow with great consideration of topography and surface characteristics of the location modelled. It takes into consideration parameters of routing, loss and flow transformation in the determination of runoff over land. It is able to perform its computation using a number of transform methods (Scharffenberg et al., 2010). A particularly important parameter is the infiltration rate as it has the highest effect in determining runoff loss (Jones, 1997). The Soil Conservation Service (SCS) Curve Number (CN), a parameter that is used to quantify infiltration and storm runoff of an area, is used in this study.

In order to obtain excess precipitation amounting to runoff, Equation 1 is used (Feldman, 2000):

$$
P_{e}=\frac{\left(P-I_{a}\right)^{2}}{P-I_{a}+S}
$$

The empirical relationship of $I_{a}$ and $S$, given as $I_{a}=0.2 S$, as developed by the SCS, the equation is given as follows (Feldman, 2000):

$$
P_{e}=\frac{(P-0.2 S)^{2}}{P+0.8 S}
$$

$\mathrm{S}$ is give as the maximum retention and this is related to the watershed characteristics through the curve number $(\mathrm{CN})$. This relationship is given as follows by Equations 3 and 4 as follows (Feldman, 2000):

$$
\begin{aligned}
& S=\frac{1000-10 \mathrm{CN}}{\mathrm{CN}} \\
& S=\frac{25400-254 \mathrm{CN}}{\mathrm{CN}}
\end{aligned}
$$

Equation 3 is used for measurements in foot - pound system. Equation 4 is used for measurements in SI units.

Where,

$P_{e}=$ Runoff (accumulated precipitation excess at time $\mathrm{t}$ in $\mathrm{mm}$ );

$P=$ accumulated precipitation depth (at time $\mathrm{t}$ in $\mathrm{mm}$ );

$S=$ potential maximum retention (a measure of the ability of the watershed to abstract and retain storm precipitation; and

$I a=$ Initial abstraction (loss).

$\mathrm{CN}$ values range from 100 (for water bodies) to approximately 30 for permeable soils with high infiltration rates. Channel routing computation is carried out with this model. It uses momentum 
equation and the continuity equation knows as St. Venant equations (Yaw et al., 2015). It accounts for forces that act on a body of water in an open channel while considering the shape of the channel. A lag method is used and this is estimated using the Curve number parameters (Feldman, 2000).

\subsection{HEC-HMS Hydrological Model development}

The main reason for modelling hydrological processes is the limitation of hydrological measurements (Yaw et al., (2015)). Hence, in order to (a) develop the hydrological model in HEC-HMS, (b) analyse the rainfall water volume and (c) estimate amount of runoff water volume over the years, three components are required - a basin model, a meteorological model and a control specifications component. Figure 3 shows the description of the HEC-HMS Hydrological Model development process.

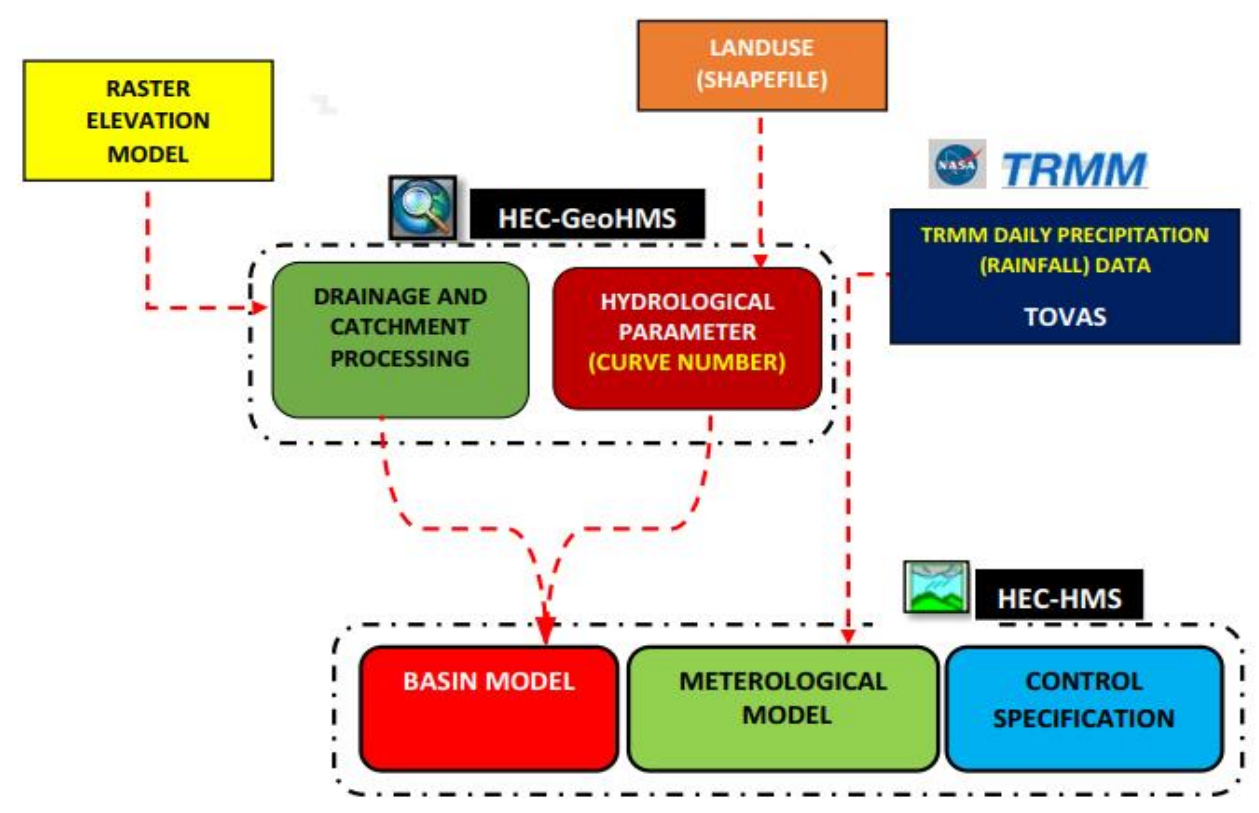

Figure 4: Hydrological Modelling process using HEC-HMS and ARCGIS

\subsubsection{Hydrological Model Parameters Estimation using HEC-GeoHMS and ARCGIS}

The basin model was created using the ArcGIS extension of HEC-HMS, HEC-GeoHMS. The LIDAR DEM served as the foundation for this process. The basin model, which is the physical component of the hydrological model, was developed using the ArcGIS extension of HEC-HMS (HEC-GeoHMS). A terrain processing, basin process and hydrological parameter computation are the key work processes carried. A brief description of these is given as follows;

- $\quad$ Terrain Processing

This is the first requirement for the creation of a basin model using this approach. This process involved the reconditioning of the DEM, spatial computation of flow direction, flow accumulation and the delineation of the catchment grid (which were required for the basin processing. 


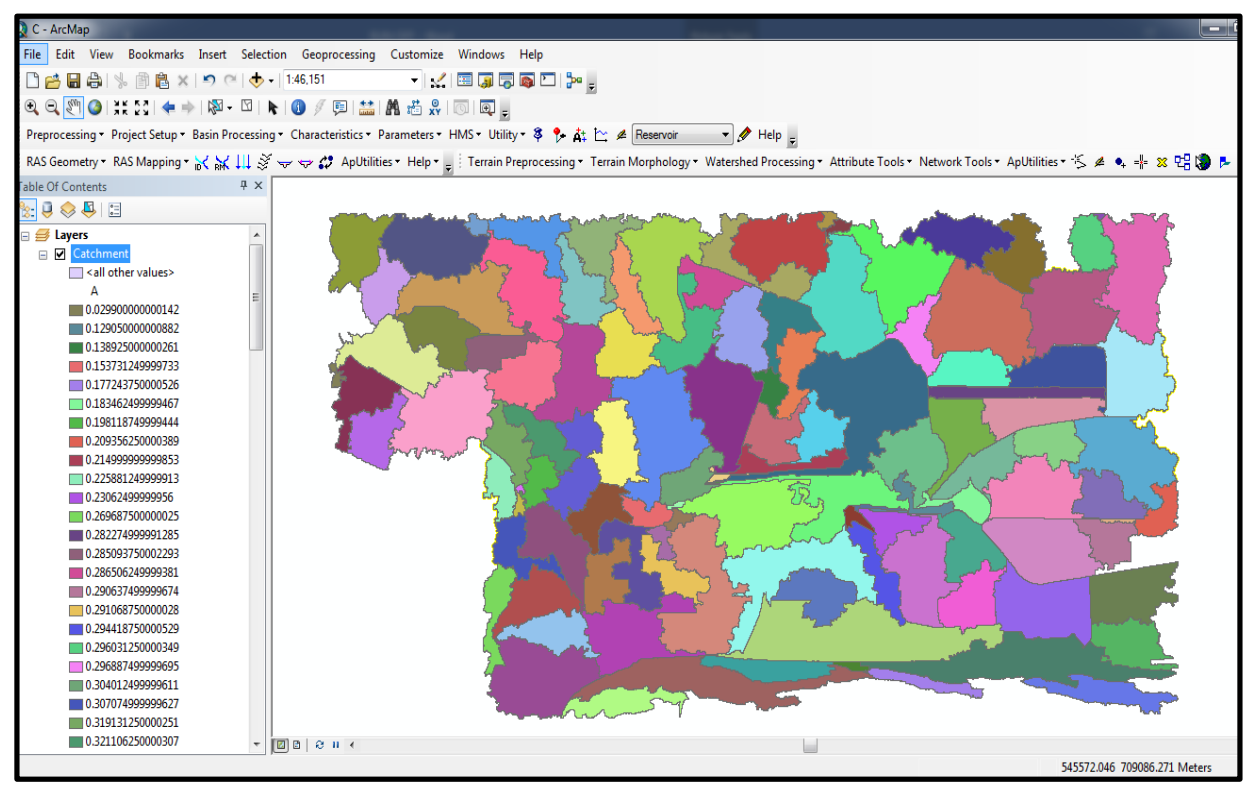

Figure 5: Catchment Grid Delineation in ArcGIS environment

- Basin Processing and characteristics determination

In order to perform the Basin Processing and characteristics determination, the HMS project was first generated, using the final output data from the terrain preprocessing. This was required because all parameters generated must be incorporated into the final basin model to be produced. At this stage, basin creation and Sub-basin division by maximum area, river merge, slope and length calculation, basin slope generation, longest flowpath, basin centroid, centroid elevation and centroid longest flowpath were determined and they form the basis for the computation of the hydrological parameters (curve numbers).

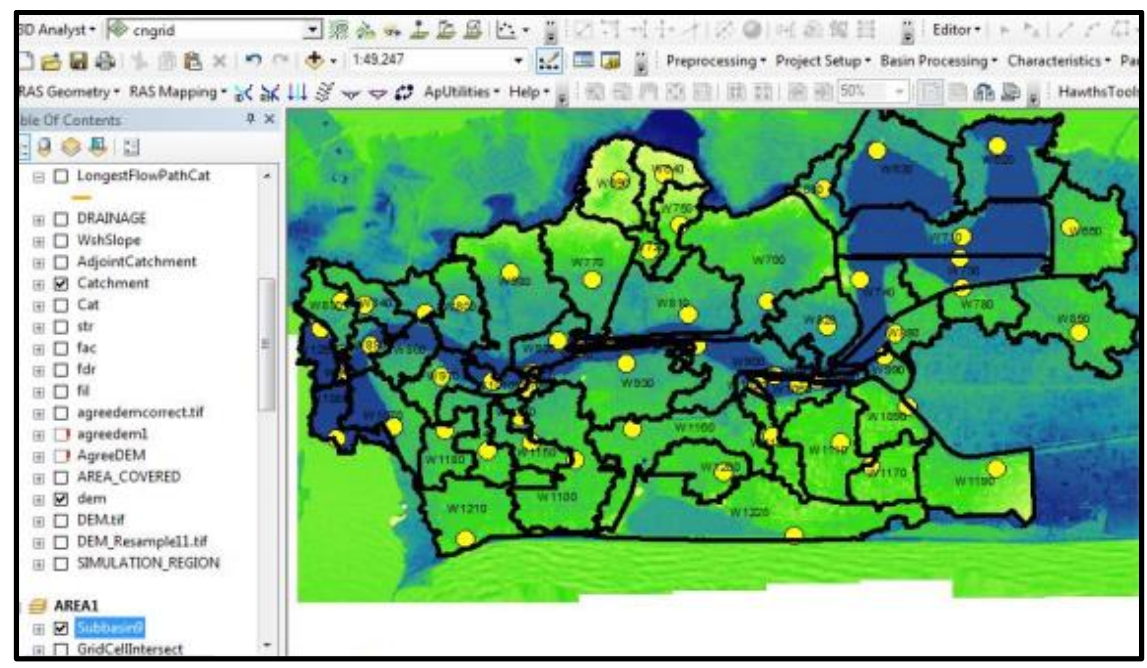

Figure 6: Basin processing in ArcGIS

- Hydrological Parameters Determination:

Before exporting the project in a format readable by HEC-HMS, HEC-GeoHMS extension was used to define distributed hydrological parameters and inputs for the project area. Using HECGeoHMS was a better option because it would take a long time to define in HEC-HMS. The Soil Conservation Service (SCS) modelling method was used. This method uses the Curve Number (CN) Grid, which is a hydrological parameter, to calculate hydrological properties for the whole basin (US-SCS, 1986). The Curve number is considered to be the most important parameter and the $\mathrm{CN}$ grid was created using landuse map, soil classification of the landuse according to the US-SCS (1986) and CN look up table created for the project. The final basin model to be used for the hydrological modelling process was generated after creating the $\mathrm{CN}$ grid. 


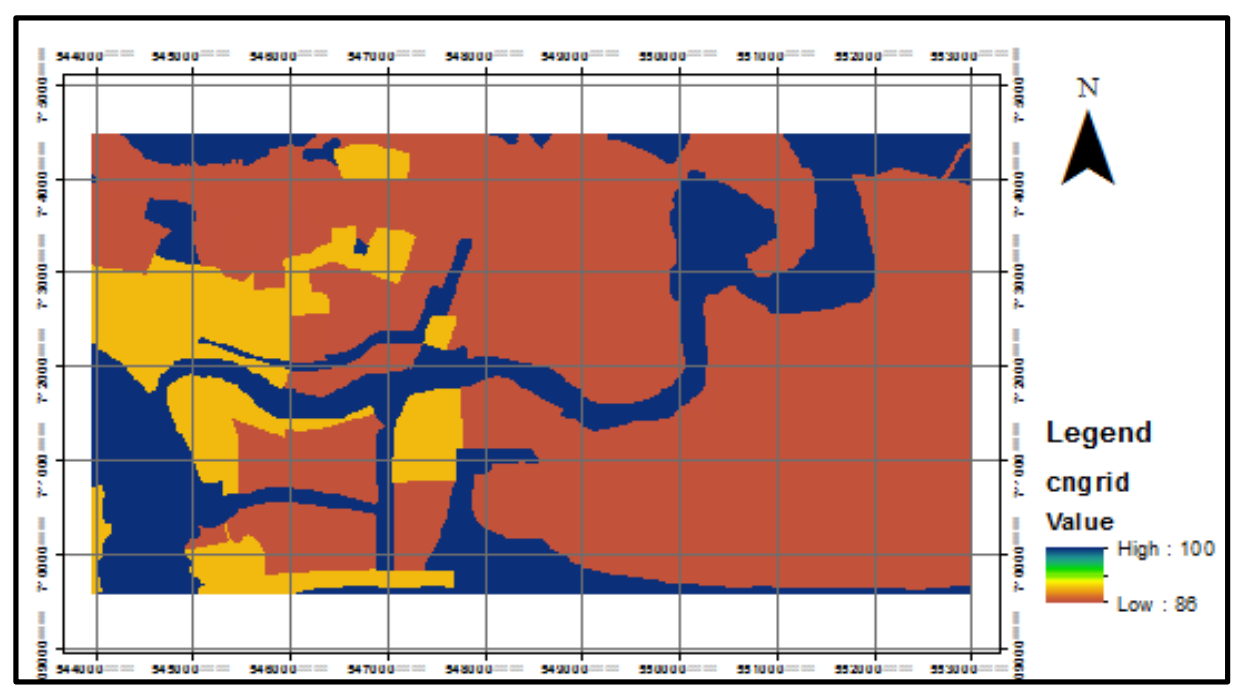

Figure 7: Curve Number $(\mathrm{CN})$ Grid

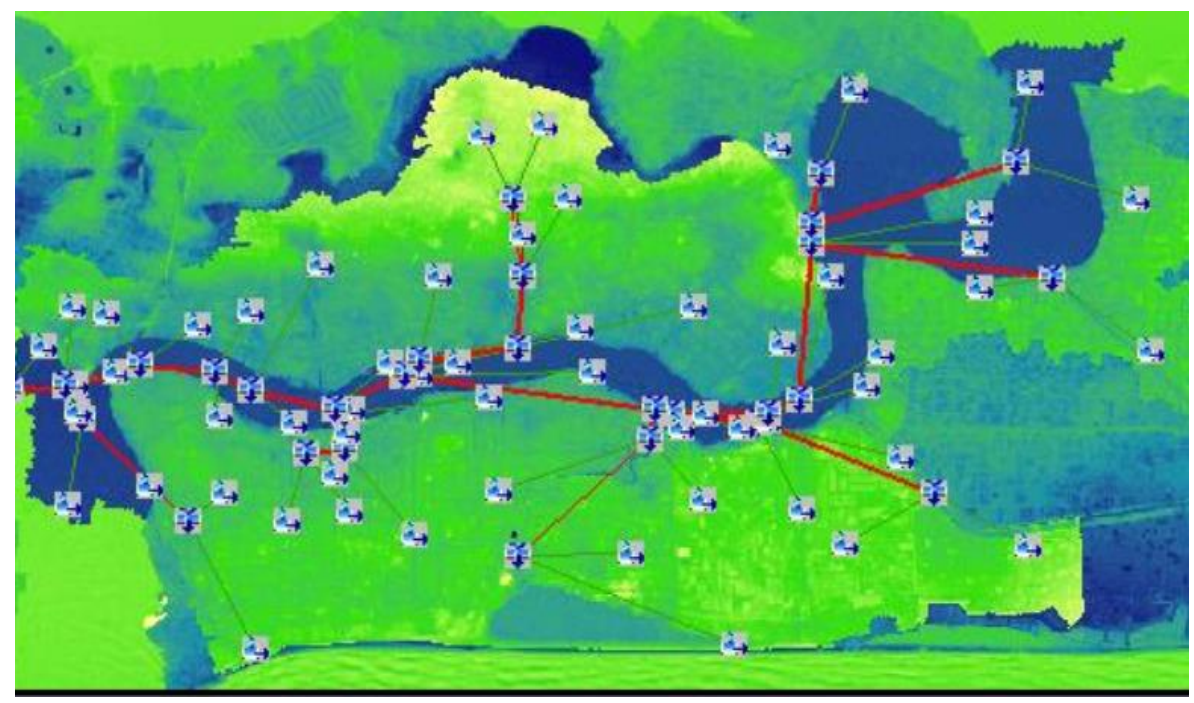

Figure 8: GIS representation of the basin model used by the hydrological model

\subsubsection{Modelling the Runoff process in HEC-HMS}

In order to model a runoff process, the Metrological Model Manager in HEC-HMS modelling package was used to develop a meteorological model. Averaged daily precipitation data obtained from TRMM for a period of ten months were added to the HEC-HMS project generated using the Time Series Manager. This process provided the model with adequate amount of rainfall data to be used in the calculation of runoff and other hydrological outputs. The control specification specifies the time window for which the model calculates discharges. Control specifications for each time window that the model makes calculations was created. The Control Specification Manager was used to create control specification for each of the years considered in this study. Thus, a 24 hours' time interval daily precipitation was obtained, the model was made to interpolate the precipitation data to produce results for a 30 minutes interval. HEC-HMS has the capability of producing results for up to 1-minute interval. 


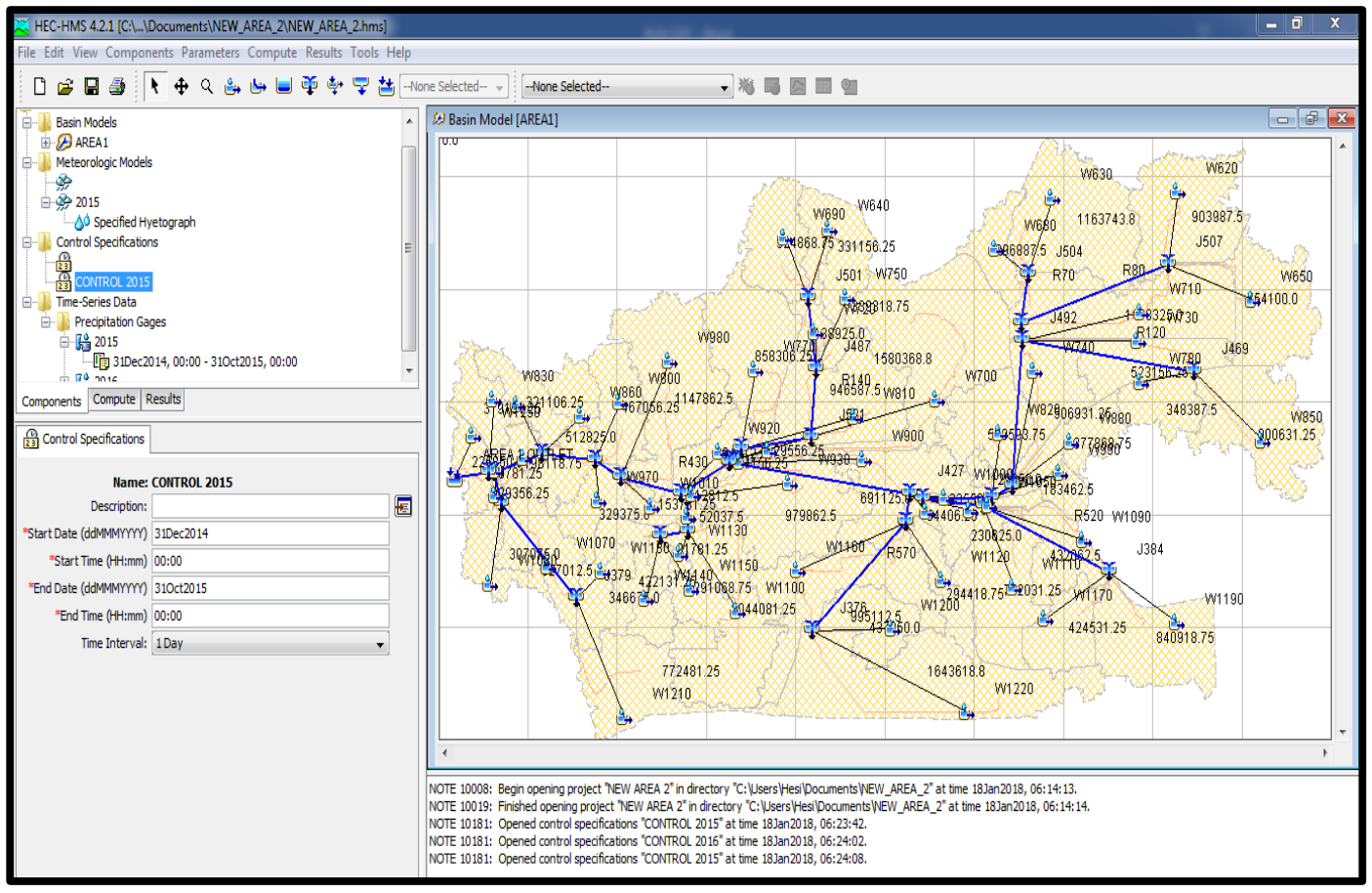

Figure 9. HEC-HMS modelling operation with Basin Model.

\subsection{Results and Discussion}

Effective application of the hydrological model depends on the practical capability of the hydrological model and the quality of the input data used. In this study, the mode is calibrated manually for a oneyear event based simulation and year 2012, 2015 and 2017 were considered and hydrological outputs (flow discharge, runoff volume and runoff depth) were obtained and compared. Figure 10 shows the diagram of the watershed (basin model) that served as the input data in HEC-HMS for the computation of the hydrological outputs.

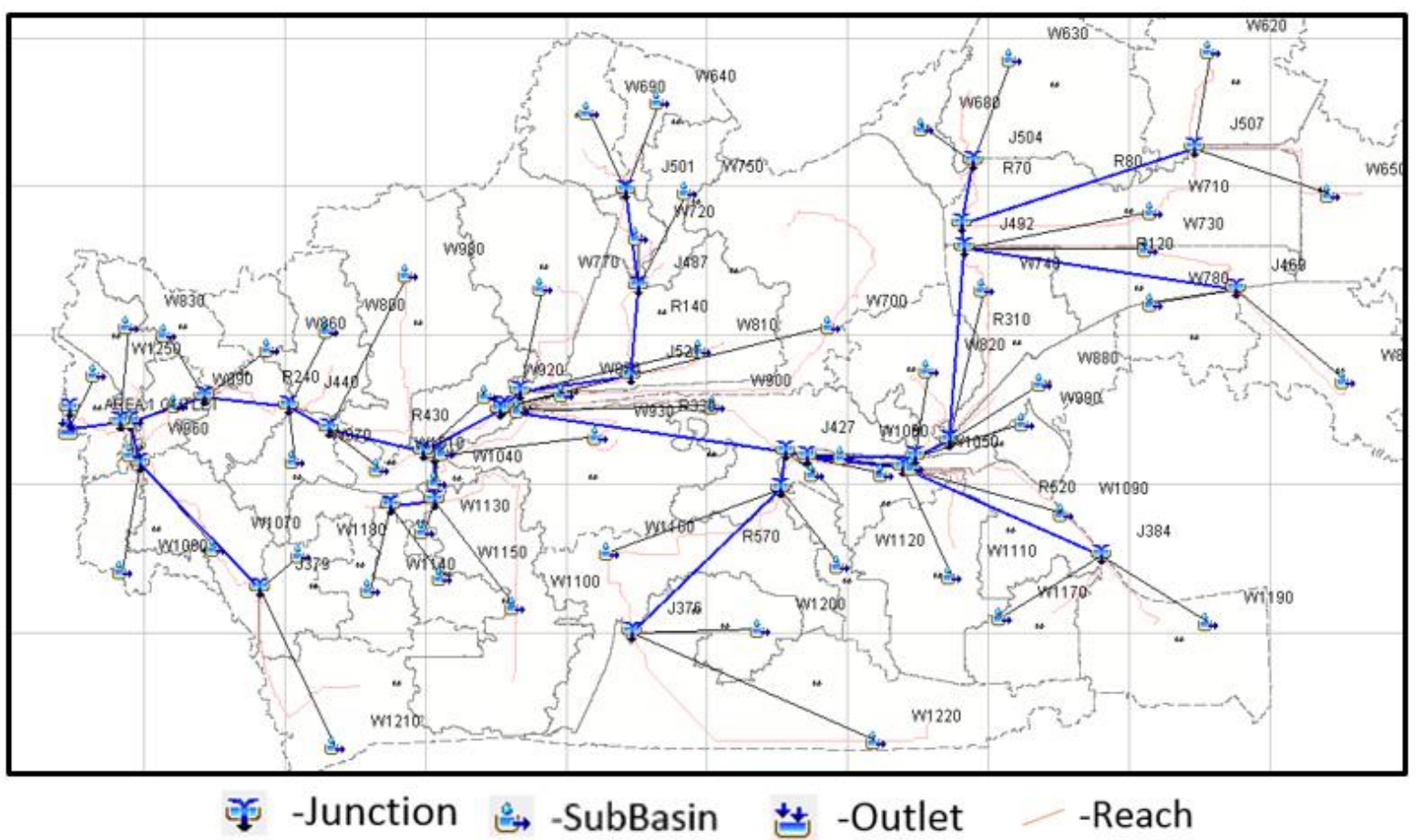

Figure 10: Diagram of watershed as HEC-HMS input 
Simulation runs were carried out for each of the years. The hydrological output estimated results were obtained from this process. Tables and Graphs showing results and analyses were extracted from the modelling package.

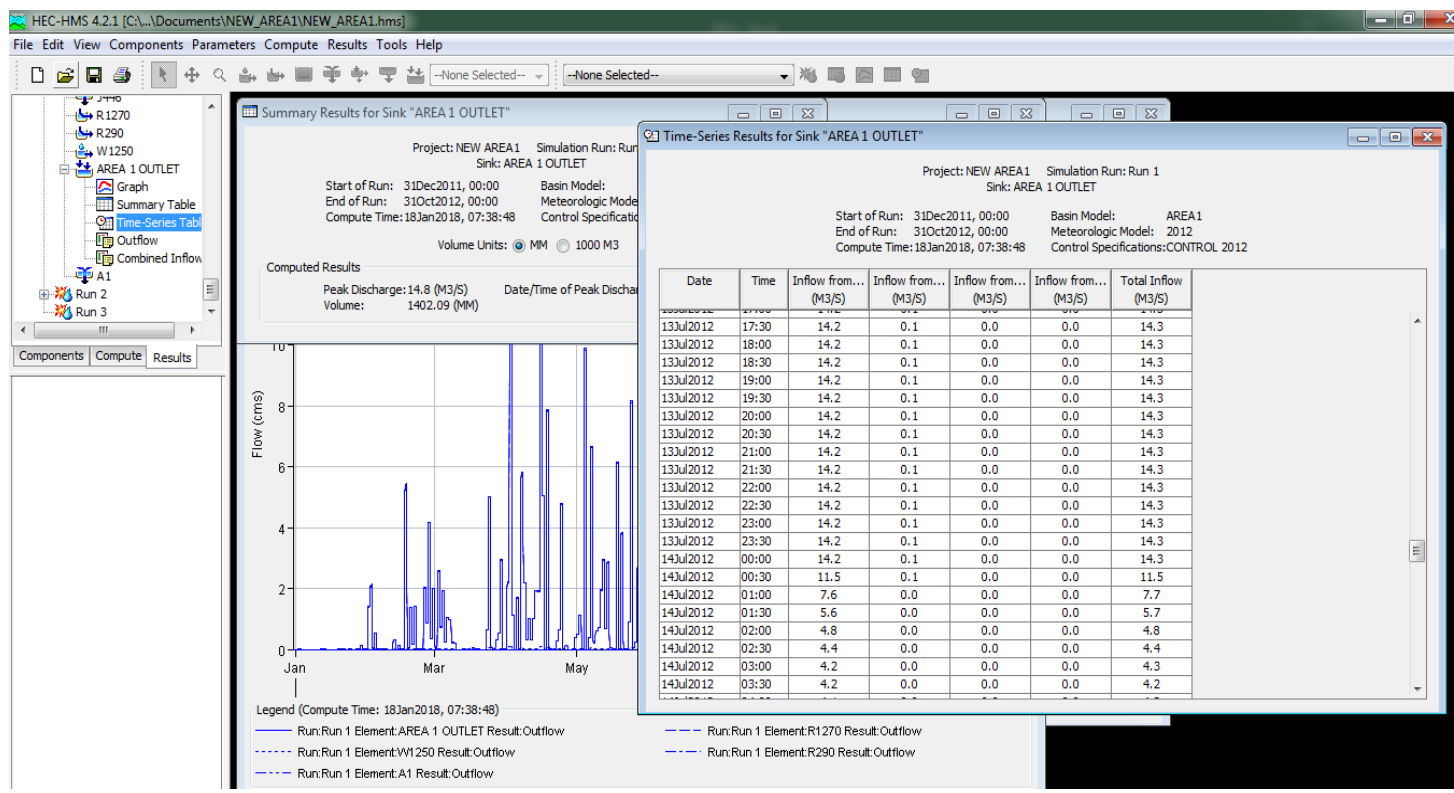

Figure 11: Showing HEC-HMS modelling and computation results (for year 2012 event)

Results obtained in this study are diverse. The Curve number and basin lag time (in minutes) extracted for each of the subbasins were obtained and these in turn were used to obtain the hydrological outputs.

The model estimated flow discharge, runoff volume and runoff depth for each subbasins, junctions and the basin outlet of the basin model.

Figures 12, 13 and 14 depict the total flow rate estimated by the model for the years considered.

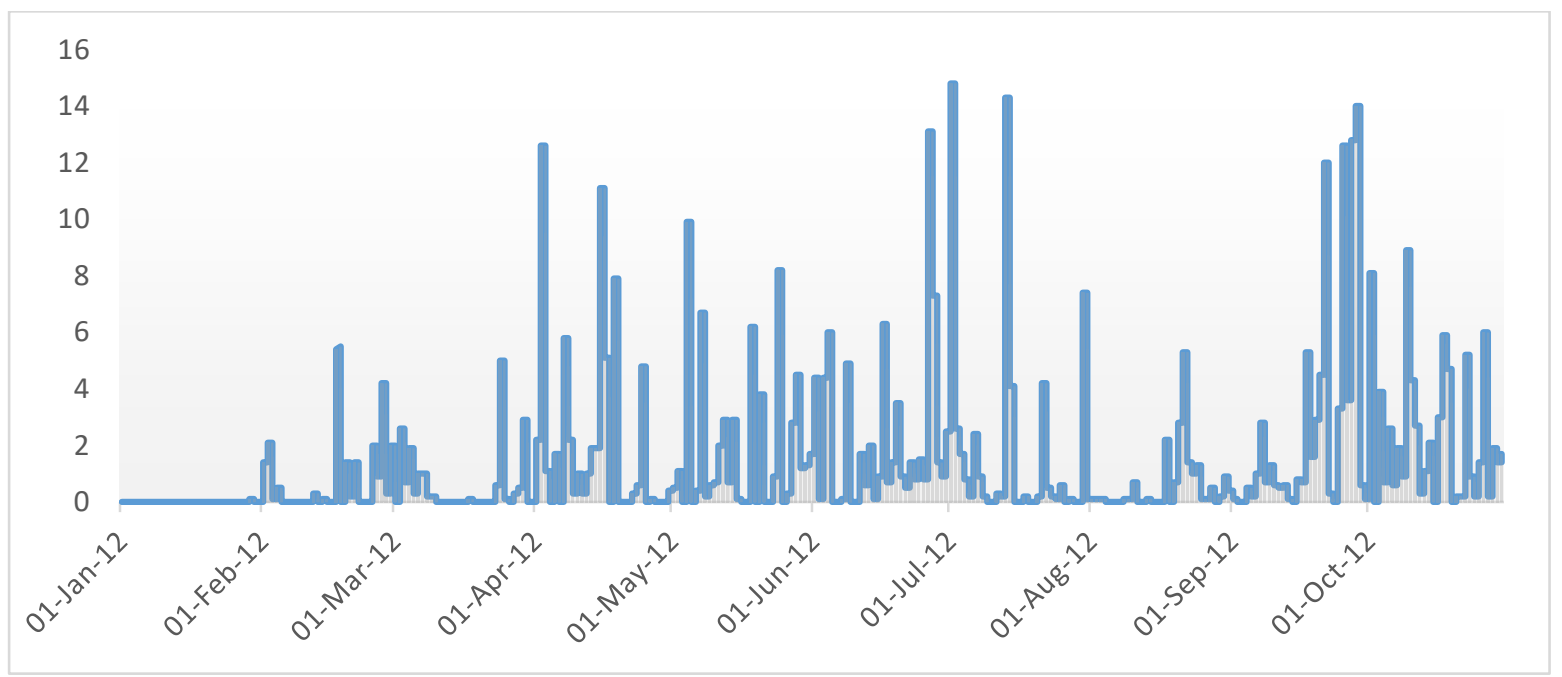

Figure 12: Estimated Flow rate for year 2012 


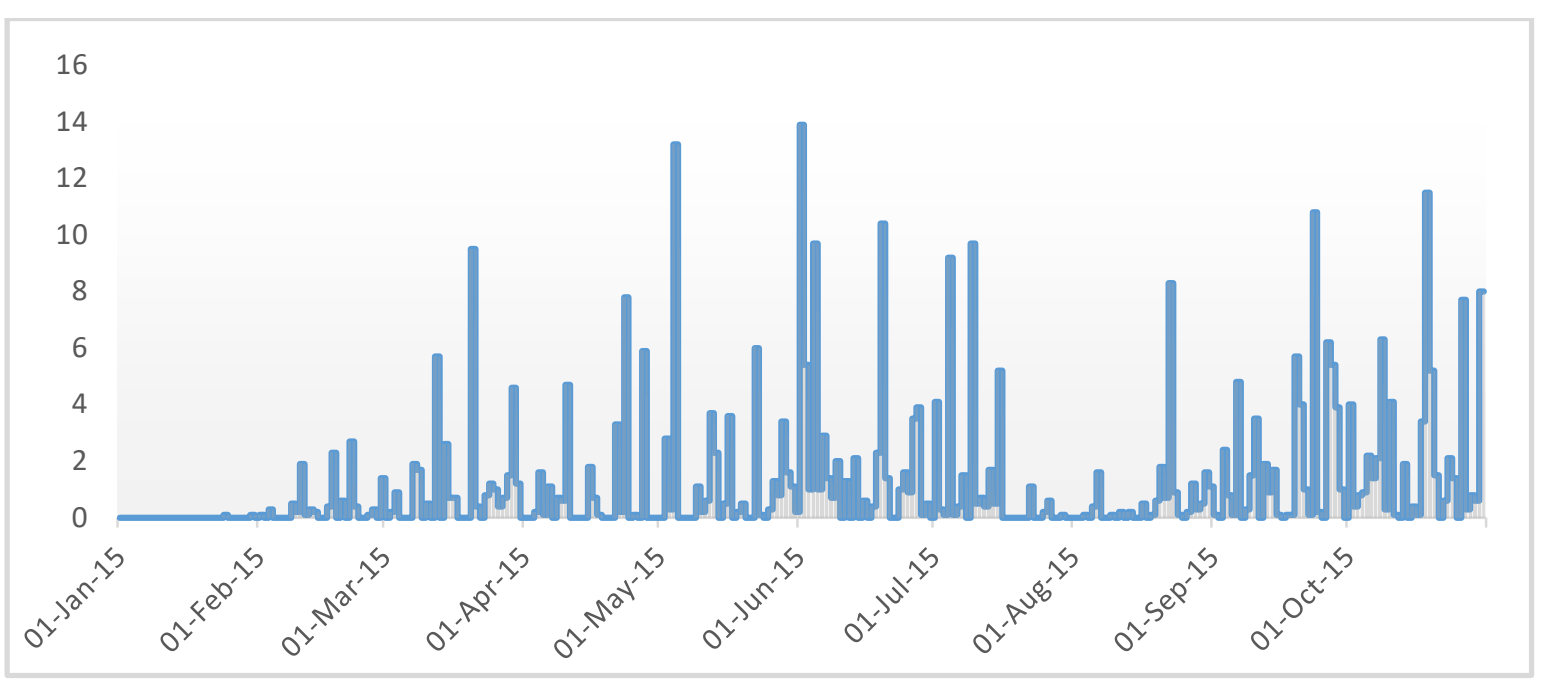

Figure 13: Estimated Flow rate for year 2015

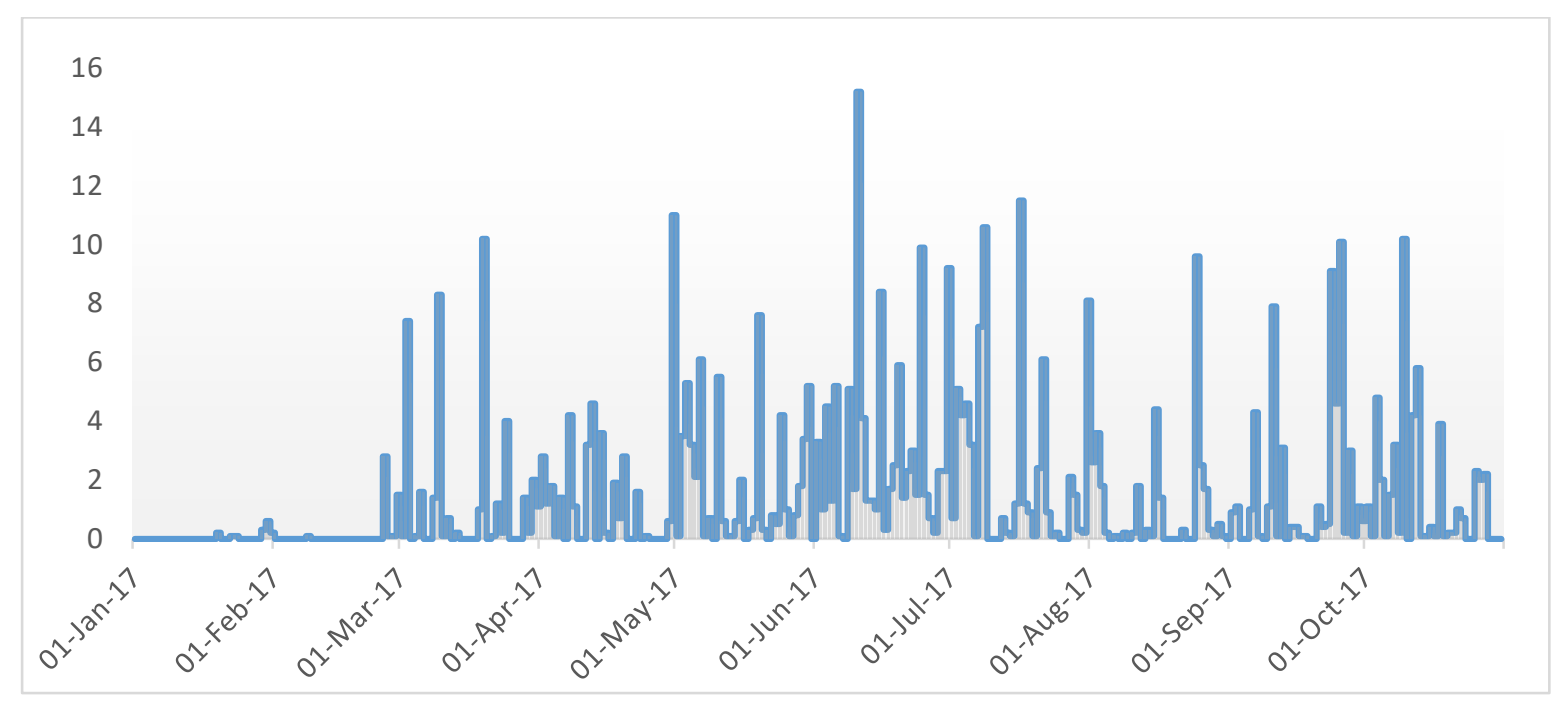

Figure 14: Estimated Flow rate for year 2017

\subsection{Analysing Peak Discharge and Runoff}

Table 1 and 2 show the results for peak discharge, time of peak, runoff depth and run of volume, respectively.

Table 1. Peak discharge with Runoff height

\begin{tabular}{ccccccc}
\hline Year & Outlet point & $\begin{array}{c}\text { Basin Area } \\
\left(\mathbf{k m}^{\mathbf{2}}\right)\end{array}$ & $\begin{array}{c}\text { Peak Discharge } \\
\left(\mathbf{m}^{\mathbf{3}} \mathbf{s}^{-\mathbf{1}}\right)\end{array}$ & $\begin{array}{c}\text { Time to } \\
\text { peak runoff }\end{array}$ & $\begin{array}{c}\text { Runoff } \\
\text { Depth (mm) }\end{array}$ & $\begin{array}{c}\text { Runoff } \\
\text { Depth }(\mathbf{m})\end{array}$ \\
\hline 2012 & AREA 1 OUTLET & 28.293 & 14.8 & 02-Jul-12 & 1402.090 & 1.402 \\
2015 & AREA 1 OUTLET & 28.293 & 10.4 & 02-Jun-15 & 1117.07 & 1.117 \\
2017 & AREA 1 OUTLET & 28.293 & 15.2 & 11-Jun-17 & 1369.480 & 1.369 \\
\hline
\end{tabular}




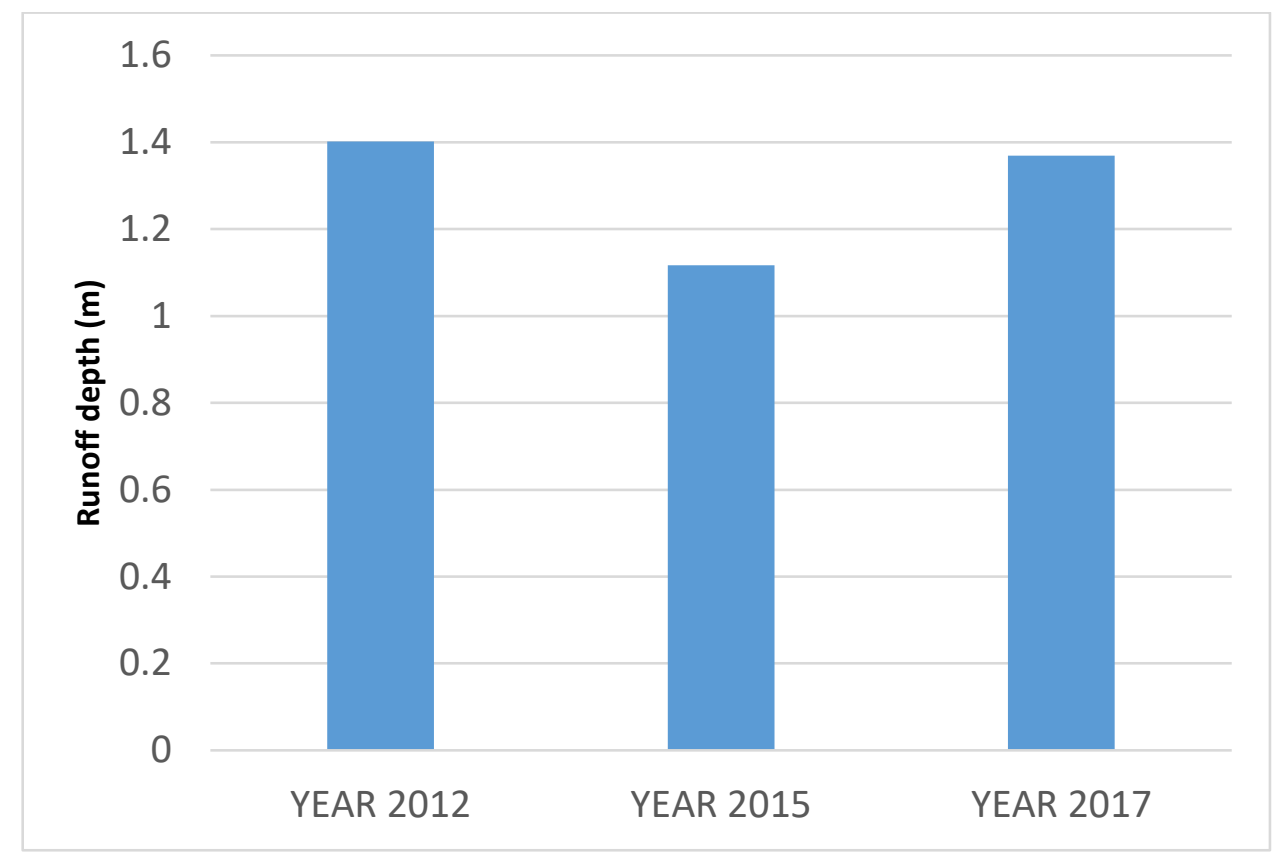

Figure 15: Estimated Runoff Depth for year 2012, 2015 and 2017

Table 2. Peak discharge with Runoff Volume

\begin{tabular}{cccccc}
\hline Year & Outlet point & $\begin{array}{c}\text { Basin Area } \\
\left(\mathbf{k m}^{\mathbf{2}}\right)\end{array}$ & $\begin{array}{c}\text { Peak Discharge } \\
\left(\mathbf{m}^{\mathbf{3}} \mathbf{- 1}\right)\end{array}$ & $\begin{array}{c}\text { Time to peak } \\
\text { runoff }\end{array}$ & $\begin{array}{c}\text { Volume of } \\
\text { Runoff } \\
\left(\mathbf{x} \mathbf{1 0}^{\mathbf{3}} \mathbf{~ m}^{\mathbf{3}}\right)\end{array}$ \\
\hline 2012 & AREA 1 OUTLET & 28.293 & 14.8 & 02-Jul-12 & 39669.700 \\
2015 & AREA 1 OUTLET & 28.293 & 10.4 & 02-Jun-15 & 31605.300 \\
2017 & AREA 1 OUTLET & 28.293 & 15.2 & 11-Jun-17 & 38747.000 \\
\hline
\end{tabular}

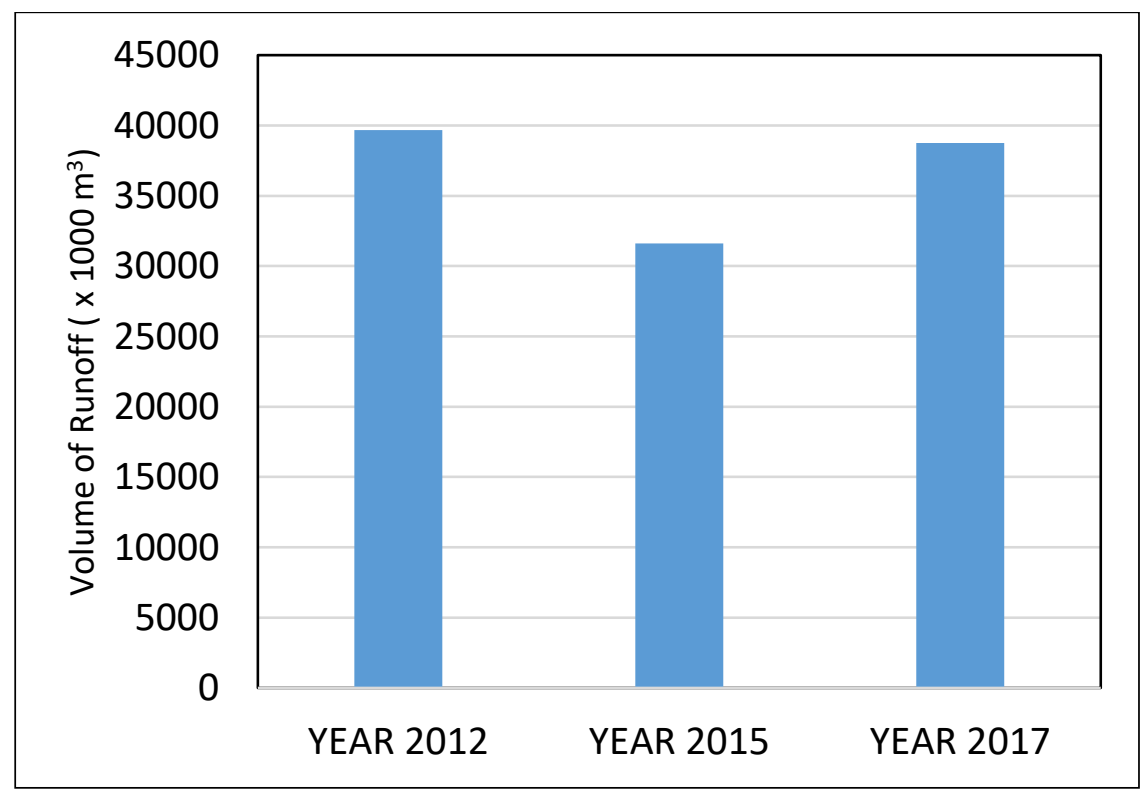

Figure 14: Estimated Rainfall Runoff Volume for year 2012, 2015 and 2017 


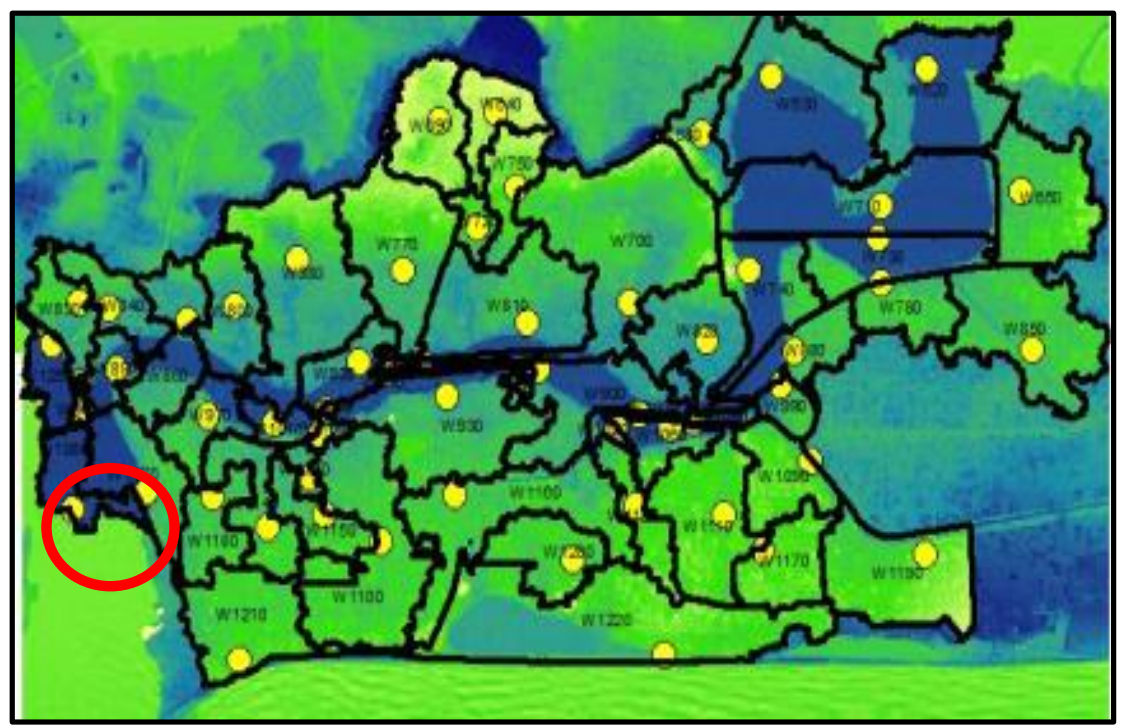

Figure 15: Showing Area 1 outlet location (area circled)

\subsection{Discussion}

The modelling system used in this study has provided results that can be useful in monitoring runoff volume and flooding in the study area. From the results depicted by Figures 12, 13 and 14, we see that the highest peak discharges estimated by the model for the time considered occurred between June and July, which is considered to be the time in which severe flooding occurs in the study area. This also shows that at these times, runoff depth and volume are very high. Increase in runoff will lead to an increase in discharge.

From the results provided in Table 1, we see peak discharge at the outlet of the basin (Area 1 Outlet), for the different years, generated for the study area. The results show that in the year 2012, peak discharge occurred on the $2^{\text {nd }}$ of July 2012 at a flow rate of $14.8 \mathrm{~m}^{3} \mathrm{~s}^{-1}$ with a runoff height of $1.402 \mathrm{~m}$. The results also show that in year 2015, peak discharge on the $2^{\text {nd }}$ of June 2015 at a flow rate of 10.4 $\mathrm{m}^{3} \mathrm{~s}^{-1}$ with a runoff height of $1.117 \mathrm{~m}$ but in year $2017,11^{\text {th }}$ of June 2017 was the time of peak discharge at a rate of $15.2 \mathrm{~m}^{3} \mathrm{~s}^{-1}$ and highest runoff depth at $1.369 \mathrm{~m}$. The results show that the times of peak discharge and runoff for these years match the periods of high rainfall and subsequently severe flood events.

The study area does not have readily available weather stations. These weather stations would have provided real time discharge and water level data that would have been used for to validate the modelling results. However, past studies such as those carried out by Majidi and Shahedi (2012); Hadi et al (2012); Reshma T. et al (2013) and Yaw et al.,(2015), validated modelling results using available hydrological data and these validation results were very satisfactory.

\subsection{Conclusion}

This study shows that Runoff estimation is mandatory to sustain the water resources and manage runoff volumes and floods in the region. In this particular study area real time, monitored data from weather stations are limited. The present study tries to study the efficiency of HEC-HMS model. After running the models repeatedly, the simulated streamflow results for each of the years considered were compared with each other. Year 2012 showed highest result in terms of runoff volume and depth and by way of face validity, it matches with the time there was severe flooding in the study area. Hence, this shows the usefulness of the HEC-HMS and its reliability in estimating, predicting and forecasting floods and runoff volumes in various watersheds.

It is therefore of great importance that great care must be taken to ensure that the data gathered for such studies are accurate. This will lead to accurate results and a further development of operational policies and regulations that should be implemented. It is also recommended that: 
i. The provision of latest weather station that will provide real time hydrological output for this study area is necessary. This will aid continuous observation of water levels and provide reliable forecast information as regards flooding.

ii. Better quality of data should be used for such study. They should be treated as a valuable resource by the relevant authorities in the proper management of water in the study area.

iii. The development of good policy and proper planning with the results obtained from this project will go a long way in reducing flooding occurrences as well as help in the control and management of such occurrences in the study area.

iv. There should be better data provision, updating and management for such projects. With this in place, the ease of the execution of such projects more frequently will be possible.

v. Proper flood warning systems should be put in place for the study area for flood monitoring processes.

\section{References}

Bates, P. D. (2004). Remote Sensing and Flood Inundation Modelling. Hydrological Processes, 18, 2593- 2597.

Castellarin, A., Di Baldassarre, G., Bates, P. and Brath, A. (2009). Optimal Cross-Sectional Spacing in Preissmann Scheme 1D Hydrodynamic Models. Journal of Hydraulic Engineering, 135, 96.

Feldman, A. D. (2000). Hydrologic Modelling System HEC-HMS: Technical Reference Manual, US Army Corps of Engineers, Hydrologic Engineering Centre.

Hadi, T., Feyzolahpur, M., Mumipour, M. and Fatemeh, Z. (2012). Rainfall-runoff Simulation and Modeling of Karun River Using HEC-RAS and HEC-HMS models, Izeh District, Iran. Journal of Applied Sciences, 12(18):1900-1908.

Horritt, M. S., and Bates, P. D. (2002). Evaluation of 1D and 2D Numerical Models for Predicting River Flood Inundation. Journal of Hydrology, 268, 87-99.

Jones, J. (1997). Global Hydrology: Processes, Resources and Environmental Management, Longman.

Knebl, M., Yang, Z. L., Hutchison, K., and Maidment, D. (2005). Regional Scale Flood Modelling using NEXRAD Rainfall, GIS, and HEC-HMS/RAS: A case study for the San Antonio River Basin Summer 2002 storm event. Journal of Environmental Management, 75, 325-336.

Majidi, A. and Shahedi. K. (2012). Simulation of Rainfall-Runoff Process Using Green-Ampt Method and HEC-HMS Model (Case Study: Abnama Watershed, Iran). International Journal of Hydraulic Engineering, 1(1): 5-9.

Olayinka, D.N. and Irivbogbe H.E. (2017). Flood Modelling and Risk Assessment of Lagos Island and Part Of Eti-Osa Local Government Areas in Lagos State. Journal of Civil and Environmental Systems Engineering, 15, 106-121.

Reshma, T., Venkata, R. K, and Deva, P. (2013). Simulation of Event Based Runoff Using HEC-HMS Model for an Experimental Watershed. International Journal of Hydraulic Engineering, 2(2): 28-33.

Scharffenberg, W. A., Fleming, M. J., and Center, H. E. (2010). Hydrologic Modelling System HECHMS: User's Manual, US Army Corps of Engineers, Hydrologic Engineering Center.

US-SCS, (1986). U.S. Soil Conservation Service. Technical Release 55: Urban Hydrology for Small Watersheds, U.S. Department of Agriculture. 